\title{
Study on the Temporal and Spatial Differentiation of Provincial Tourism Efficiency in Eastern China and Influencing Factors
}

\author{
Huadi Wang $\mathbb{D}^{1},{ }^{1}$ Shaogui $\mathrm{Xu},{ }^{2}$ Qiuyi Xie, ${ }^{3}$ Jianying Fan, ${ }^{4}$ and Nianxing Zhou $\mathbb{D}^{3}$ \\ ${ }^{1}$ School of Education Science, Nanjing Normal University, Nanjing, Jiangsu 210046, China \\ ${ }^{2}$ School of Management, Jinan University, Guangzhou, Guangdong 510630, China \\ ${ }^{3}$ School of Geography, Nanjing Normal University, Nanjing, Jiangsu 210023, China \\ ${ }^{4}$ School of Tourism and Culture, Nanning Normal University, Nanning, Guangxi 530100, China \\ Correspondence should be addressed to Nianxing Zhou; zhounianxing@263.net
}

Received 22 June 2021; Revised 10 August 2021; Accepted 9 September 2021; Published 4 October 2021

Academic Editor: Jun Li

Copyright ( $\odot 2021$ Huadi Wang et al. This is an open access article distributed under the Creative Commons Attribution License, which permits unrestricted use, distribution, and reproduction in any medium, provided the original work is properly cited.

\begin{abstract}
Tourism efficiency can be used to effectively measure the utilization of regional tourism resources and the state of tourism economic development. Based on the super efficiency DEA model, Malmquist index, and spatial econometric model, this article measures the static and dynamic tourism efficiency of 11 provinces and cities in eastern China for 2010 to 2019. In combining ArcGIS 10.0 and MATLAB 2016b software, this article studies the temporal and spatial differentiation of tourism efficiency in eastern provinces and cities and influencing factors. The results show that (1) the overall tourism efficiency of eastern provinces is at a high level and relatively stable, but the regional distribution is quite varied, and problems of spatial imbalance are prominent; (2) the overall tourism efficiency of eastern provinces is increasing, and the change index of technical efficiency contributes the most, followed by the change index of scale efficiency; and (3) industrial status, traffic conditions, tourism resource endowment, and the labour force are the main factors affecting the temporal and spatial differentiation of tourism efficiency in eastern provinces and cities, while the level of economic development and information technology have no significant impact.
\end{abstract}

\section{Introduction}

At present, China's economy is transitioning from a stage of rapid growth to a stage of high-quality development. Tourism plays an important role in optimizing the economic structure, promoting the transformation of growth drivers, and meeting people's spiritual and cultural needs to meet their desire for a better life. It is also crucial for China under the current new normal to improve tourism efficiency and take the path of sustainable development. As an effective index of resource utilization capability and effect based on input-output [1], efficiency can effectively measure the comprehensive impact of tourism on a region to make a corresponding evaluation of the tourism development of different provinces and cities. It is of great significance to promote the development of regional tourism and increase tourism economic income to systematically evaluate the tourism efficiency of various provinces and cities through time and space.

Domestic and foreign research on tourism efficiency has been carried out from many dimensions, and the research results are relatively comprehensive. In terms of the object of research, researchers have examined the tourism efficiency of different levels of tourism destinations, different types of tourism activities, and tourism departments with different functions [2-5]. In terms of research content, researchers have conducted beneficial explorations of the efficiency of tourism poverty alleviation [6], tourism resource conversion [7], and tourism ecological development [8, 9]. In addition to conducting research on the efficiency of tourism hotels, tourism transportation, tourism destinations, and travel agencies from a micro perspective [10], domestic scholars 
have also carried out research at the macro and meso levels in examining urban agglomerations, provinces, cities, and counties as well as at the micro level in studying scenic areas and forest parks [11-16]. The scope, depth, methodologies, and intersectionality of research on tourism efficiency are also expanding [10]. Despite this work, research on the eastern China economic belt, a leading area of tourism economic development, is still relatively limited. Taking 11 provinces and cities in eastern China as its basic research unit, this study constructs an index system of tourism efficiency measurement using data related to tourism and the economy for 2010 to 2019. The static super efficiency DEA model and dynamic Malmquist index are used to measure the level and development trends of tourism efficiency in China's eastern provinces and cities. Meanwhile, with the help of a spatial econometric model, the authors analyse the temporal and spatial differentiation characteristics and influencing factors of regional tourism efficiency from the perspective of space and visualization and regulate and predict differences in tourism efficiency. This work is expected to promote the high-quality development of the tourism economy in China's eastern region and guide the tourism economic development of China's central and western provinces, which started later and lags behind that of China's eastern provinces, to facilitate the development of China's tourism economy.

\section{Study Area and Data}

2.1. Study Area. To formulate long-term national economic development plans, land development and renovation plans, and regional layout and regional economic development policies and services, China is divided into three major economic zones: the eastern, central, and western regions. The eastern economic zone is located in the eastern region of Asia, along the eastern border of the Eurasian continent and along the west coast of the Pacific Ocean, covering a total area of approximately 950,000 square kilometres. The region includes three cities, Beijing, Tianjin, and Shanghai, and eight provinces, Hebei, Liaoning, Jiangsu, Zhejiang, Fujian, Shandong, Guangdong, and Hainan, with a total of 11 provincial administrative units. Due to the influence of its geographic location, development foundations, market conditions, and human capital, the region has formed the most developed socialist economy in China. All of the major metropolises of mainland China, such as Beijing, Shanghai, Shenzhen, and Guangzhou, are located in eastern China. Therefore, it is appropriate and significant to use the DEAMalmquist index combined with the exploratory spatial data analysis method to conduct an in-depth study of tourism efficiency in this area.

\subsection{Data Source and Index Selection}

2.2.1. Data Source. To ensure the study's authenticity, integrity, and continuity, all data used are from the China Statistical Yearbook (2010-2019) and China Tourism Statistical Yearbook (2010-2019) as well as from the statistical yearbooks of eastern provinces and cities and the Statistical
Bulletin of National Economic and Social Development (2010-2019). Due to missing data for some years for some provinces and cities, interpolation is adopted to supplement the data to ensure the rationality of calculations and meet the processing requirements of this study.

\subsubsection{Index Selection}

(1) Setting of Input-Output Elements of Tourism Efficiency. The index of tourism efficiency evaluation often adopts the production input factors of economics, which are generally defined as land and natural resources, labour, capital, and so on [17]. Among these, the impact of land on tourism development is relatively limited, and the number of starred hotels and A-level scenic areas receiving capital investment also reflects the scale of land investment to a certain extent, so it is not taken as an input variable [18]. The labour force injects vitality into regional tourism development, representing an important source of potential for its development. However, due to the lack of data on the ideal input index of tourism practitioners, on the basis of increasing the number of employees, the selection of employees in the tertiary industry as labour input can be regarded as a means of index selection in line with the characteristics of the tourism industry. Capital factors mainly include various tourism service facilities and enterprises that promote the development of the tourism industry. We use the number of A-level scenic areas, star hotels, and travel agencies that reflect the value of tourism resource endowment and the reception and service capacity of the tourism industry as input variables of capital [19]. Tourism output factors mainly include economic effects, social effects, and ecological effects. To reduce the impacts of other external environmental variables, such as travel convenience, travel preferences, and city reputation, we use domestic tourism income and the number of domestic tourists as output indicators to reflect economic and social effects. Based on the change in the statistical standard of the total area of afforestation, the area of artificial afforestation for a given year is used as the index of ecological effect output (Table 1).

(2) Setting of Influencing Factors of Tourism Efficiency. As tourism efficiency is affected by macro- and micro-level aspects, the following six factors are used based on the existing literature [20-22]. (1) The economic development level (ECON): the level of economic development directly affects tourism project cooperation between provinces and urban areas and then affects the development of tourism efficiency. Improving infrastructure, introducing advanced technology, and innovating tourism products require a certain degree of capital investment. Here, the variable is expressed by the per capita GDP of provinces and cities. (2) Industrial status (STAT): the status of the tourism industry can reflect the government's attention to regional tourism development to a certain extent and reflect the agglomeration capacities of regional tourism factors. The stronger this capacity is, the broader the flow of regional tourism production factors becomes. We use the proportion of domestic 
tourism income of GDP to express the state of the tourism industry. (3) Tourism resource endowment (RESO): tourism resource endowment affects the flow and allocation of tourism investment elements between provinces and cities as well as tourism flow and tourism investment, thus affecting the division of labour and cooperation in the tourism industry between provinces and cities. The evaluation rules of the national standard classification and of the quality of scenic areas (GB/T17775-2003) are adopted. The minimum score for scenic areas specified by Rule 2 is selected as the score for the resource endowment evaluation of scenic areas at corresponding levels. The resource endowment evaluation value of the decision-making unit is obtained by summing the scores for all scenic areas above grade 3A of the unit [23]. (4) Traffic conditions (TRAN): tourism resources in the eastern provinces are distributed unevenly across space, and traffic conditions greatly affect the development of tourism. As highways represent the most important form of provincial and municipal transportation, the highway mileage $(\mathrm{km})$ of each province and city is used to represent traffic conditions. (5) The labour force (HR): the tourism industry is a labour-intensive industry. Labour indirectly affects the development efficiency and performance of the tourism economy. The number of employees in the tertiary industry is used to represent the labour force. (6) The information development level (INFO): the informatization development level affects the spatial agglomeration and expansion of the tourism economy and can be expressed by the total level of post and telecommunications business. However, due to the lack of statistical calibre and data for certain years, the total amount of postal business is used to express this value.

\section{Methods}

3.1. Super Efficiency DEA Model. The DEA (Data Envelopment Analysis) model was first proposed by Charnes, Cooper, and Rhodes in 1978. DEA is a new field that integrates operational research, mathematical economics, and management science [24] and that uses mathematical programming models, including linear programming, multiobjective programming, generalized optimization with a tapered structure, semi-infinite programming, and random programming, to evaluate the relative effectiveness of multiple inputs and/or output "departments" or "units" (DMU) [25]. DEA is a commonly used means to measure economic efficiency and can effectively measure tourism efficiency. However, due to the particularities of the tourism industry, the corresponding input variables are relatively controllable, while the output variables are not. We use the input-oriented model of the DEA method and the method proposed by Andersen and Petersen [26]. The super efficiency model of the improved CCR designed to further distinguish the effectiveness of effective DMU is used to evaluate and rank the research objects. Assuming $n$ role units, input variable $X_{i j}(I=1,2, \ldots, m)$ in $m$ and output variable $Y_{i j}(r=1,2, \ldots, p)$ in $P$, the super efficiency CCRDEA calculation model is written as follows:

$$
\begin{aligned}
& \min \left[\theta-\varepsilon\left(\sum_{i=1}^{m} S_{i}^{-}+\sum_{r=1}^{p} S_{r}^{+}\right)\right], \\
& \text {s.t. }\left\{\begin{array}{l}
\sum_{j=1, j \neq k}^{n} \lambda_{j} x_{i j}+S_{i}^{-}=0 x_{0}, \quad i=1,2, \ldots, m, \\
\sum_{j=1, j \neq k}^{n} \lambda_{j} y_{i j}-S_{r}^{+}=y_{0}, \quad r=1,2, \ldots, p, \\
\lambda_{j} \geq 0, \quad j=1,2, \ldots, n, \\
S_{i} \geq 0 \\
S_{r} \geq 0 .
\end{array}\right.
\end{aligned}
$$

In the formula, $X_{0}$ and $y_{0}$ are input and output vectors of selected decision unit $\mathrm{DUM}_{0}$, respectively; $\lambda$ is the combination ratio of $n$ decision units in an effective $\theta$ combination newly constructed relative to $\mathrm{DUM}_{0} ; S_{i}^{-}$and $S_{r}^{+}$are relaxation variables of input and output, respectively; and $\theta$ is the comprehensive efficiency value of DMU. When $\theta<1$, DMU is non-DEA effective. When $\theta \geq 1$, DMU is DEA effective; the greater $\theta$ is, the higher the level of efficiency is [27].

3.2. Malmquist Index. As the change in tourism efficiency involves a dynamic process, tourism efficiency will change with time. The relative efficiency calculated by the static DEA model cannot be compared with the optimal efficiency frontier constructed by it; that is, the value cannot be directly compared with tourism efficiency over the years. Therefore, the Malmquist index is introduced to conduct an intertemporal analysis of tourism efficiency and a dynamic evaluation of tourism efficiency [28]. The Malmquist index of total factor productivity was first proposed by Malmquist (1953) and later improved by Fare R (1994). The Malmquist Index (MI) is expressed as follows [29]:

$$
\mathrm{MI}_{t+1}=\left[\frac{D^{t+1}\left(x^{t+1}, y^{t+1}\right)}{D^{t+1}\left(x^{t}, y^{t}\right)} \times \frac{D^{t}\left(x^{t+1}, y^{t+1}\right)}{D^{t}\left(x^{t}, y^{t}\right)}\right]^{1 / 2} .
$$

In the formula, $D_{t}\left(x^{t+1}, y^{t+1}\right)$ represents the distance between the DMU in period $t+1$ and the production front surface in period $t$; that is, all DMUs in period $t$ are used to construct the production front surface to measure the efficiency of a DMU in period $t+1$. $\mathrm{MI}_{t+1} \in(0,+\infty)$. If $\mathrm{MI}_{t+1}>1$, then compared with that of period $t$, the tourism efficiency of period $t+1$ is higher. If $\mathrm{MI}_{t+1}<1$, then compared with that of period $t$, the tourism efficiency of period $t+1$ is lower. If $\mathrm{MI}_{t+1}=1$, relative to period $t$, there is no change in tourism efficiency in period $t+1$.

\subsection{Spatial Weight Matrix Setting}

3.3.1. Spatial Autocorrelation Test. Before setting the spatial weight matrix, the spatial data should be analysed to determine the nonrandomness or spatial autocorrelation of distribution. This approach involves spatial analysis with a 
recognition function. By identifying and distinguishing the characteristics of geographic data and then observing the atypical location, we find the corresponding spatial correlation, clustering, or hot spot pattern; connect the geographic space to the data space; and determine the spatial correlation of economic activities. We use Moran's I index to explore the spatial correlation of regional comprehensive tourism efficiency. The specific formula used is as follows:

$$
\begin{aligned}
\text { Moran's } I & =\frac{n}{S_{0}} \times \frac{\sum_{i=1}^{n} \sum_{j=1}^{n} W_{i j}\left(X_{i}-\bar{X}\right)\left(X_{j}-\bar{X}\right)}{\sum_{i=1}^{n}\left(X_{i}-\bar{X}\right)^{2}}, \\
S_{0} & =\sum_{i=1}^{n} \sum_{j=1}^{n} W_{i j} .
\end{aligned}
$$

In the formula, $n$ is the province, $X_{i}$ is the observed value of province $i$, and $W_{i j}$ represents the spatial weight matrix. The Moran's $I$ index value ranges from -1 to 1 . According to Moran's $I$ index value, spatial distribution in the study area can be determined. At a given significance level, a Moran's I of $>0$ indicates a positive correlation, that is, the units in the study area are spatially clustered; if Moran's $I$ is $<0$, this indicates a negative correlation, that is, each unit in the study area is distributed discretely across space; and if Moran's $I=0$, the space is uncorrelated, that is, each unit in the study area presents an irregular random distribution.

3.3.2. Spatial Weight Matrix. The spatial weight matrix reflects the interdependence of individuals in space. The value is an important basis for further spatial data analysis.
In this article, the geographic adjacency weight matrix is used as the spatial weight matrix, and the form is set as follows:

$$
W_{i j}= \begin{cases}1, & \text { If } i \text { is adjacent to } j \text { and } i \neq j, \\ 0, & \text { If } i \text { is not adjacent to } j \text { or } i=j .\end{cases}
$$

That is, when two provinces are adjacent, the value is 1 ; otherwise, it is 0 . At the same time, for our robustness test, we use the geographic distance weight matrix for our spatial econometric analysis. The form of the geographic distance spatial weight matrix is set as follows:

$$
W_{i j}= \begin{cases}1 / d_{i j}^{2}, & i \neq j, \\ 0, & i=j .\end{cases}
$$

In the formula, $d_{i j}^{2}$ represents the surface distance of latitude and longitude between two cities, and $i \neq j$. When $i=j, W_{i j}$ is 0 , and the geographic attenuation index is 2 .

3.4. Spatial Measurement Model Setting. Spatial panel models can effectively solve the problems of spatially explained variable autocorrelation and measurement error and mainly include the spatial lag model (SLM), spatial error model (SEM), and spatial Dobbin model (SDM) [30]. Considering the possible spatial spillover effect of tourism efficiency and influencing factors in provinces and cities in eastern China, based on the basic spatial panel model, the model is constructed as follows:

$$
y_{i t}=\beta_{0}+\beta_{1} \mathrm{ENCO}_{i t}+\beta_{2} \mathrm{STAT}_{i t}+\beta_{3} \mathrm{RESO}_{i t}+\beta_{4} \mathrm{TRAN}_{i t}+\beta_{5} \mathrm{HR}_{i t}+\beta_{6} \mathrm{INFO}_{i t}+\mu_{i}+\varepsilon_{i t} .
$$

In the formula, $i$ is the province, $t$ is the year, and $y_{i t}$ is the comprehensive tourism efficiency level (calculated by the super efficiency DEA model). $\mathrm{ENCO}_{i t}$ is the level of economic development. STAT $i t$ is the industrial status (measured by the proportion of domestic tourism revenue of GDP); $\mathrm{RESO}_{i t}$ is the endowment of tourism resources; TRAN $_{i t}$ denotes traffic conditions. $\mathrm{HR}_{i t}$ is the labour force, and $\mathrm{INFO}_{i t}$ is the information level. $\mu_{i}$ is the individual fixed effect, and $\varepsilon_{i t}$ is the error term.

In addition, in view of the possible omission of location factors and other variables in the setting of the econometric model, these unobservable missing variables may also have an impact on the comprehensive efficiency of tourism and lead to spatial dependence, so it is necessary to include the spatial effect in the econometric analysis. The specific spatial measurement model is set as follows:

$$
\begin{aligned}
& y_{i t}=\alpha+\rho \sum_{j=1, j \neq i}^{N} W_{i j} y_{i t}+\beta X_{i t}+\sum_{j=1, j \neq i}^{N} W_{i j} X_{i t} \theta+\mu_{i}+v_{t}+\varepsilon_{i t}, \\
& \varepsilon_{i t}=\varphi \sum_{j=1, j \neq i}^{N} W_{i j} \varepsilon_{i t}+\phi_{i t} .
\end{aligned}
$$

In the formula, $\varepsilon_{i t}$ is the error term; $\mu_{i}$ and $\nu_{t}$ represent the unobservable regional effect and time effect, respectively; $\rho$ and $\varphi$ are the spatial lag coefficient and spatial error coefficient, respectively; $W_{i j}$ is the spatial weight matrix, and $X$ is the independent variable vector including the economic development level, industrial status, tourism resource endowment, traffic conditions, labour force, and the information level. Formula (7) is a general nested model of the spatial interaction effect. In the empirical analysis, according to $\rho, \varphi$ and $\theta$, the spatial econometric model is also different depending on whether the value is 0 .

\section{Results and Analysis}

4.1. Comprehensive Tourism Efficiency Analysis. Based on the data measurement based on the DEA model, the comprehensive tourism efficiency of 11 eastern provinces and cities from 2010 to 2019 is calculated with the help of DEA-Solver software. According to the results (Table 2), the overall tourism efficiency of the eastern provinces and cities is higher than that shown in Table 1 for the past decade. Across provinces and cities, the tourism efficiency of each region varies. Hainan Province has the lowest comprehensive tourism efficiency $(0.588)$, whereas other 
Table 1: Descriptive statistics of input-output indices and original data for eastern provinces and cities for 2010 to 2019.

\begin{tabular}{|c|c|c|c|c|c|c|c|}
\hline Indices & Indicator & Unit & Definition & Maximum & Minimum & Mean & $\begin{array}{l}\text { Standard } \\
\text { deviation }\end{array}$ \\
\hline \multirow{4}{*}{$\begin{array}{l}\text { Input } \\
\text { indicators }\end{array}$} & $\begin{array}{l}\text { Number of employees in } \\
\text { the tertiary industry }\end{array}$ & $\begin{array}{l}\text { Ten thousand } \\
\text { people }\end{array}$ & $\begin{array}{c}\text { The potential and vitality of } \\
\text { tourism }\end{array}$ & 3378.02 & 165.87 & 1255.18 & 682.31 \\
\hline & $\begin{array}{c}\text { Number of A-level scenic } \\
\text { areas }\end{array}$ & Home & $\begin{array}{l}\text { The value of tourism } \\
\text { resource endowment }\end{array}$ & 1292 & 52 & 317.45 & 259.96 \\
\hline & $\begin{array}{c}\text { Number of star-rated } \\
\text { hotels }\end{array}$ & Home & $\begin{array}{l}\text { The reception capacity of } \\
\text { the tourism industry }\end{array}$ & 1175 & 71 & 456.18 & 295.97 \\
\hline & Number of travel agencies & Home & $\begin{array}{l}\text { The service capacity of the } \\
\text { tourism industry }\end{array}$ & 3281 & 301 & 1420.66 & 736.35 \\
\hline \multirow{3}{*}{$\begin{array}{l}\text { Output } \\
\text { indicators }\end{array}$} & Domestic tourism revenue & $\begin{array}{l}\text { One hundred } \\
\text { million yuan }\end{array}$ & $\begin{array}{c}\text { The overall economic level } \\
\text { of the region }\end{array}$ & 13902.21 & 235.61 & 4713.31 & 3121.61 \\
\hline & $\begin{array}{l}\text { Number of domestic } \\
\text { tourists }\end{array}$ & $\begin{array}{l}\text { Thousands of } \\
\text { people }\end{array}$ & The level of social activity & 93288.00 & 2521.03 & 35863.14 & 20974.24 \\
\hline & Current afforestation area & $\begin{array}{c}\text { Thousands of } \\
\text { hectares }\end{array}$ & $\begin{array}{c}\text { The ecological environment } \\
\text { of the tourism area }\end{array}$ & 371.77 & 0.71 & 72.86 & 88.70 \\
\hline
\end{tabular}

provinces and cities have comprehensive tourism efficiency levels of higher than 0.8 , and most provinces and cities have higher levels of tourism efficiency.

In terms of time, the overall tourism efficiency of eastern provinces and cities from 2010 to 2019 maintains a high level, does not change much, shows no significant continuous increase or decrease, or first increases and then decreases or vice versa. The highest efficiency value for 10 years is 1.307, and the lowest value is 1.097. In 2009, the government defined tourism as a strategic pillar industry. The Opinions of the State Council on Accelerating the Development of Tourism in 2009 reported that all efforts should be made to promote investment in and the development of the tourism industry. Several Opinions on Promoting the Reform and Development of Tourism in 2014 called for strengthening and creating room for tourism development. The support and promotion of numerous policies have greatly promoted the development of tourism and the improvement and stability of tourism efficiency.

In terms of regional distribution, there are great differences in comprehensive tourism efficiency among provinces and cities, and the degree of polarization is serious. The average value of comprehensive efficiency over 10 years for Hebei Province is the highest (2.050), and the value for Hainan Province is the lowest (0.588). Among the 11 provinces, the average efficiency levels for Hebei, Tianjin, and Shanghai are higher than 1.5, ranking in the first echelon. The average efficiency levels of Liaoning, Fujian, and Guangdong are higher than 1 but lower than 1.5, ranking in the second echelon. The average efficiency levels of Beijing, Jiangsu, Zhejiang, Shandong, and Hainan are less than 1, and the average efficiency level of Hainan is less than 0.5, ranking in the third echelon. In summary, most provinces and cities in eastern China show high degrees of tourism efficiency and excellent development results. At the same time, the results show that the annual distribution of tourism efficiency is relatively stable and that the regional distribution is unbalanced.
4.2. Dynamic Tourism Efficiency Analysis. Using DEAP2.1 software, the Malmquist index of total factor productivity and its changes in 11 provinces and cities of eastern China from 2010 to 2019 were calculated and decomposed. Among the values measured, the total factor productivity index is measured as the comprehensive efficiency change index$x$ technological progress, and the efficiency change index is also measured as the pure technical efficiency change index $\times$ the scale efficiency change index $\times$ the technological progress efficiency change index. In other words, the total factor productivity index can be decomposed into the comprehensive efficiency change index and the technological progress efficiency change index, and the comprehensive efficiency change index can be further decomposed into the pure technical efficiency change index and the scale efficiency change index. Through the decomposition of the total factor productivity index, dynamic tourism efficiency can be more clearly analysed.

On the time dimension (Table 3), the total factor productivity of eastern provinces and cities from 2010 to 2019 was higher than 1, indicating that total factor productivity was still on the rise. In the nine periods of tourism efficiency evaluation, the change index of comprehensive efficiency for five periods is higher than 0.95 but less than 1 , the change index of comprehensive efficiency for four periods is higher than 1 , the change across nine periods show no special signs of regularity, and the average change index of comprehensive efficiency is 0.999 . In terms of technological progress efficiency, except for the two periods of 2011-2012 and 2014-2015, the efficiency change index of the other seven periods is higher than 1 , and the average value of the technical efficiency change index is 1.065 . From a comparative point of view, the change index of technological progress efficiency is the most important driving force of tourism efficiency, while the change index of comprehensive efficiency restricts the improvement of tourism efficiency to a certain extent. After decomposing the comprehensive efficiency change index into pure technical efficiency and the scale efficiency change index, it is found that the pure technical efficiency change index and scale efficiency change 
TABLe 2: Values and ranking of comprehensive tourism efficiency levels in eastern provinces and cities for 2010 to 2019.

\begin{tabular}{lccccccccccccc}
\hline DMU & 2010 & 2011 & 2012 & 2013 & 2014 & 2015 & 2016 & 2017 & 2018 & 2019 & Mean & Ranking \\
\hline Beijing & 0.797 & 0.814 & 0.833 & 0.866 & 0.920 & 0.910 & 0.871 & 0.838 & 0.796 & 0.741 & 0.839 \\
Tianjin & 1.846 & 1.818 & 1.807 & 2.099 & 1.446 & 2.075 & 1.963 & 1.871 & 1.916 & 1.871 & 1.871 \\
Hebei & 1.303 & 0.912 & 1.496 & 1.822 & 2.250 & 2.649 & 2.091 & 2.763 & 2.315 & 2.898 & 2.050 \\
Liaoning & 1.370 & 1.223 & 1.326 & 1.281 & 1.242 & 1.142 & 1.197 & 1.260 & 1.203 & 1.227 & 1.247 & 4 \\
Shanghai & 1.859 & 1.702 & 1.918 & 1.826 & 1.223 & 1.942 & 1.737 & 1.673 & 1.381 & 1.240 & 1.650 & 3 \\
Jiangsu & 0.734 & 0.734 & 0.769 & 0.823 & 0.909 & 0.972 & 0.998 & 0.988 & 0.975 & 0.954 & 0.886 & 7 \\
Zhejiang & 0.723 & 0.794 & 0.828 & 0.851 & 0.890 & 1.056 & 0.997 & 0.960 & 0.911 & 0.882 & 0.889 & 6 \\
Fujian & 0.722 & 2.557 & 1.165 & 1.201 & 0.703 & 0.850 & 0.801 & 0.943 & 0.861 & 0.885 & 1.069 & 5 \\
Shandong & 1.052 & 0.825 & 0.819 & 0.885 & 0.794 & 0.895 & 0.804 & 0.826 & 0.796 & 0.776 & 0.847 \\
Guangdong & 0.899 & 0.894 & 1.036 & 1.174 & 1.341 & 1.308 & 1.222 & 1.092 & 0.982 & 0.744 & 1.069 & 5 \\
Hainan & 0.765 & 0.507 & 0.652 & 0.460 & 0.439 & 0.577 & 0.621 & 0.619 & 0.616 & 0.626 & 0.588 & 10 \\
Mean & 1.097 & 1.162 & 1.150 & 1.208 & 1.105 & 1.307 & 1.209 & 1.258 & 1.159 & 1.168 & 1.182 & \\
\hline
\end{tabular}

TABle 3: Overall dynamic tourism efficiency changes of eastern provinces and cities divided by time.

\begin{tabular}{lccccc}
\hline Time & $\begin{array}{c}\text { Comprehensive efficiency } \\
\text { (effech) }\end{array}$ & $\begin{array}{c}\text { Efficiency of } \\
\text { technological progress (techch) }\end{array}$ & $\begin{array}{c}\text { Pure technical } \\
\text { efficiency (pech) }\end{array}$ & $\begin{array}{c}\text { Scale } \\
\text { efficiency } \\
\text { (sech) }\end{array}$ & $\begin{array}{c}\text { Total factor productivity } \\
\text { (tfpch) }\end{array}$ \\
\hline $2010-2011$ & 0.977 & 1.250 & 1.005 & 0.972 & 1.220 \\
$2011-2012$ & 1.052 & 0.974 & 1.004 & 1.048 & 1.025 \\
$2012-2013$ & 0.988 & 1.049 & 0.998 & 0.989 & 1.036 \\
$2013-2014$ & 1.010 & 1.025 & 1.000 & 1.010 & 1.035 \\
$2014-2015$ & 1.032 & 0.988 & 0.993 & 1.039 & 1.019 \\
$2015-2016$ & 0.990 & 1.094 & 1.002 & 0.987 & 1.082 \\
$2016-2017$ & 1.009 & 1.049 & 0.995 & 1.015 & 1.058 \\
$2017-2018$ & 0.976 & 1.092 & 0.987 & 0.989 & 1.066 \\
$2018-2019$ & 0.966 & 1.090 & 0.993 & 0.972 & 1.053 \\
Mean & 0.999 & 1.065 & 0.997 & 1.002 & 1.065 \\
\hline
\end{tabular}

index are higher than 1 in five periods and less than 1 in four periods. The average efficiency change indexes of the two are 0.977 and 1.002 , respectively. This reveals problems with the operation, management, and technologies of the tourism industry over the last ten years. While improving tourism efficiency relying on industrial scale is more effective, this cannot achieve outstanding results. Therefore, the change index of technical efficiency is the main factor that affects the improvement of tourism efficiency in eastern provinces and cities. In descending order, the indexes affect the tourism efficiency total factor productivity index as follows: the technical efficiency change index, scale efficiency change index, and pure technical efficiency change index.

For provinces and cities (Table 4), the average TFP of 11 eastern provinces and cities from 2010 to 2019 is 1.062, and the TFP index of each province and city is higher than 1. Among the values, the average growth rate of the comprehensive efficiency change index is $-0.1 \%$, the average growth rate of the technological progress efficiency change index is $6.2 \%$, the average growth rate of the pure technical efficiency change index is $-0.3 \%$, and the average growth rate of the scale efficiency change index is $0.2 \%$. Therefore, the overall high level of tourism efficiency found in eastern provinces is mainly due to improvements to the efficiency of technological progress, indicating that the utilization of tourism resources and the management level of the tourism industry in this region have been effectively improved. Further subdivision shows that the improvement of the total factor productivity indexes of Tianjin, Hebei, Liaoning,
Shanghai, Jiangsu, Zhejiang, and Fujian is jointly driven by comprehensive efficiency and technological progress efficiency. These seven provinces and cities should further improve the management level of the tourism industry by maintaining the current level of tourism efficiency. The comprehensive efficiency change indexes of Beijing, Guangdong, Shandong, and Hainan are less than 1, so the improvement of their total factor production efficiency is mainly driven by the efficiency of technological progress. To increase comprehensive efficiency, these four provinces and cities should formulate measures to improve their own resource utilization levels and support talent according to their low pure technical efficiency or scale efficiency.

\subsection{Temporal and Spatial Differentiation and Influencing Factor Analysis}

4.3.1. Temporal and Spatial Differentiation. Based on the analysis of the index of tourism development efficiency and total factor productivity for 11 eastern provinces and cities, it is necessary to judge whether there are some correlations based on the spatial relations between provinces and cities and whether these correlations will change with time. According to Formula (3), the panel Moran's I index value of tourism comprehensive efficiency is -0.2486 , which is significant at the significance level of $5 \%$, indicating that after controlling the explanatory variables, tourism comprehensive efficiency shows a significant spatial correlation, and 
TABle 4: Average values of dynamic tourism efficiency for 11 provinces and cities in eastern China from 2010 to 2019.

\begin{tabular}{lccccc}
\hline $\begin{array}{l}\text { Province or } \\
\text { city }\end{array}$ & $\begin{array}{c}\text { Comprehensive } \\
\text { efficiency (effech) }\end{array}$ & $\begin{array}{c}\text { Efficiency of technological } \\
\text { progress (techch) }\end{array}$ & $\begin{array}{c}\text { Pure technical } \\
\text { efficiency (pech) }\end{array}$ & $\begin{array}{c}\text { Scale efficiency } \\
\text { (sech) }\end{array}$ & $\begin{array}{c}\text { Total factor productivity } \\
\text { (tfpch) }\end{array}$ \\
\hline Beijing & 0.992 & 1.071 & 0.970 & 1.022 & 1.062 \\
Tianjin & 1.000 & 1.094 & 1.000 & 1.000 & 1.094 \\
Hebei & 1.000 & 1.123 & 1.000 & 1.000 & 1.123 \\
Liaoning & 1.000 & 1.062 & 1.000 & 1.000 & 1.062 \\
Shanghai & 1.000 & 1.013 & 1.000 & 1.000 & 1.013 \\
Jiangsu & 1.030 & 1.060 & 1.000 & 1.030 & 1.092 \\
Zhejiang & 1.022 & 1.053 & 1.000 & 1.022 & 1.021 \\
Fujian & 1.023 & 1.010 & 1.002 & 0.972 & 1.064 \\
Shandong & 0.972 & 1.094 & 1.000 & 0.979 & 1.038 \\
Guangdong & 0.979 & 1.060 & 1.000 & 0.978 & 1.028 \\
Hainan & 0.978 & 1.052 & 0.997 & 1.002 & 1.062 \\
Mean & 0.999 & 1.062 & &
\end{tabular}

tourism comprehensive efficiency is distributed discretely among provinces. To further explore the spatial distribution characteristics of comprehensive tourism efficiency in eastern provinces and cities, the comprehensive tourism efficiency of eastern provinces and cities is spatially clustered and visualized in 2010, 2015, and 2019 (Figure 1).

4.3.2. Analysis of Influencing Factors. According to Moran's I index, we find a significant spatial correlation for provincial comprehensive tourism efficiency in eastern China. Therefore, the spatial econometric model is used to analyse the influencing factors of comprehensive tourism and to analyse the direct, indirect, and total spatial spillover effects of each influencing factor to clarify the action mechanism of the influencing factors. According to Elhorst's research [31], the use of the spatial lag model (SAR), spatial error model (SEM), or spatial Doberman model (SDM) is judged through calculation. The specific test results are shown in Table 5.

Since the spatial lag model with spatial fixed effects is more suitable for estimating the econometric equation of formula (7), we estimate the spatial lag model with spatiotemporal dual fixed effects. To facilitate comparison, MATLAB 2016b and its spatial measurement software package are used to estimate and test the relevant models of six factors influencing tourism efficiency in 11 provinces and cities in eastern China, and the results of the panel fixed effect model are displayed in Table 6. According to Table 6, the $p$ value of the measurement results of the provincial spatial SAR model for eastern China is significantly different from 0 , indicating significant spatial effects in all regions.

From the model measurement estimation results, the coefficients of various variables of the SAR model have both significant positive and negative effects and insignificant effects. Among them, the impact of economic development and information levels on tourism efficiency is not significant. Tourism resource endowment and the labour force have significant negative effects on tourism efficiency. The impact of industrial status and traffic conditions on tourism efficiency is positive. Specifically, we find the following:

(1) The level of economic development, as an important indicator of the scale and speed of regional economic development, shows high levels of productivity and talent attraction. Although this measure can have a certain impact on tourism efficiency in all areas of tourism investment and tourism demand, the more developed the economy is, the better outcomes are, because tourism and other industries also compete for policies and economic resources. Regarding regional tourism efficiency, while vigorously developing the regional economy, paying attention to the investment and policy preferences of the tourism industry is key to improve tourism efficiency, especially in economically developed areas of China's eastern region.

(2) The level of informatization is of certain significance to the development and innovation of regional tourism. The renewal and use of advanced technology can help the tourism industry reduce its dependence on human factors and have an impact on the comprehensive management of tourism facilities and tourists' participation in tourism activities. In terms of improving tourism efficiency, the variable failed to pass the significance test. To improve innovation in the tourism industry and promote the sustainable development of tourism, the information level should play a more important role in tourism development and further affect the tourism efficiency of eastern provinces and cities.

(3) Tourism resource endowment is an important basis for regional tourism development. Tourist attractions are critical in helping provinces and cities to develop tourism. The quality and quantity of tourism attractions are of great significance to the development of tourism. The negative effect of tourism resource endowment on tourism efficiency coincides with resource curse theory. Rich tourism resources do not necessarily equate to high tourism efficiency [32]. In addition to their insufficient utilization of tourism resources, different provinces and cities lack cooperation in tourism resource development, the interregional division of labour and cooperation is unreasonable, and the development of tourism resources and the noncooperative game of tourism products will also affect tourism efficiency. 

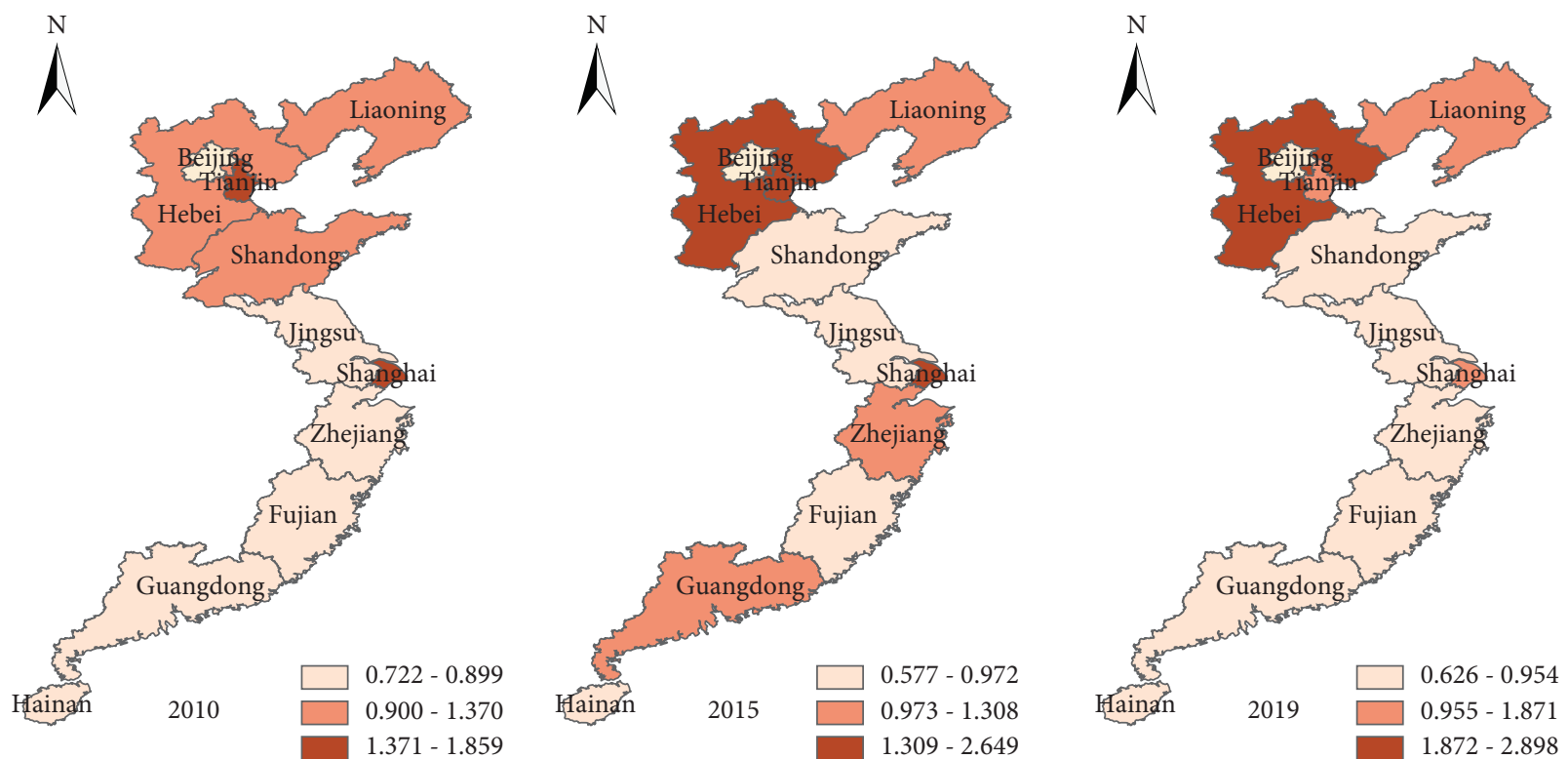

FIgURE 1: Spatial Distribution map of comprehensive Tourism efficiency (part).

(4) The labour force indirectly affects the development efficiency and performance of the tourism economy. As a labour-intensive industry, the tourism industry has certain requirements for the labour force. However, this does not mean that the more tourism practitioners there are, the higher the level of tourism efficiency will be, in turn meeting the needs of the regional tourism industry. At the same time, too many low-skilled employees may also be an important reason for the negative correlation found between the labour force and tourism efficiency. Therefore, on the one hand, the eastern provinces and cities should formulate differentiated incentive policies for tourism practitioners according to different levels of economic development; on the other hand, these entities should also absorb an appropriate amount of labour according to the needs of the industry.

(5) Industrial status is mainly reflected in attention to industry and the optimization of the industrial structure. Relevant policies can lay a foundation and good external conditions for the development of the tourism industry, and the optimization and upgrading of industrial structure can promote the healthy development of the tourism industry and improve tourism efficiency. Industrial status has a significantly positive impact on tourism efficiency. To improve tourism efficiency, the tourism industry must be a focus and its industrial structure must be optimized.

(6) Traffic conditions support the development of tourism and directly affect the sustainable development of the sector in various provinces and cities. The development of transportation changes the breadth and depth of the spatial economic ties of the tourism industry within provinces and cities to a certain extent and affects tourists' access to areas, and the resulting psychological and spatial distance jointly act on tourists' tourism motivations and demands and can attract more investment from tourism investors. To create more room for tourism development, more development space can be obtained. Therefore, traffic conditions have an important positive impact on the tourism efficiency of all eastern provinces and cities. The continuous improvement of traffic conditions will be critical to promoting the development of regional tourism and should be given sufficient attention.

To more thoroughly and accurately interpret the influencing and transmission effects of the explanatory variables on the explained variables, we continue to analyse direct, indirect, and total spatial spillover effects using a spatial SAR model. Here, LeSage and Pace's method [33] is used to further estimate the spatial spillover effect in the spatial lag model (Table 7). The direct effect reflects the impact of explanatory variables such as the level of regional economic development on comprehensive tourism efficiency. The indirect effect represents the spatial spillover effect of explanatory variables such as the effect of the level of regional economic development on the comprehensive tourism efficiency of surrounding provinces. The overall spatial spillover effect is the sum of the direct spatial spillover effect and indirect spatial spillover effect. Among these effects, the indirect spatial spillover effect does not pass the significance test, so we mainly analyse the direct spatial spillover effect and total spatial spillover effect.

The direct spatial spillover effect is also known as the intraregional spillover effect. Table 7 shows that the spillover effects of industrial status, traffic conditions, tourism resource endowment, and the labour force on tourism efficiency pass the significance test. The first two factors have positive effects, and the latter two have negative effects, 
TABLE 5: Spatial metrological test results.

\begin{tabular}{|c|c|c|c|}
\hline \multirow{2}{*}{ Content evaluation methods } & \multirow{2}{*}{ Inspection methods } & \multicolumn{2}{|c|}{ Geographic adjacency matrix } \\
\hline & & Statistics & Probability \\
\hline \multirow{4}{*}{ SAR model and SEM model test } & LM-lag test & 6.1879 & 0.013 \\
\hline & R-LM-lag test & 2.2481 & 0.134 \\
\hline & LM-err test & 4.1682 & 0.041 \\
\hline & R-LM-err test & 0.2283 & 0.633 \\
\hline \multirow{2}{*}{ Fixed effect test for spatial Dubin model } & SFE-LR & 118.5147 & 0.0000 \\
\hline & TFE-LR & 15.1073 & 0.1282 \\
\hline Hausman test of SDM model & Hausman test & 58.2209 & 0.0000 \\
\hline \multirow{4}{*}{ Simplified test of SDM model } & Wald-lag test & 1.3323 & 0.9698 \\
\hline & LR-lag test & 1.4864 & 0.9604 \\
\hline & Wald-err test & 2.2124 & 0.8992 \\
\hline & LR-err test & 2.4679 & 0.8720 \\
\hline
\end{tabular}

TABle 6: Spatial metering estimation results.

\begin{tabular}{|c|c|c|}
\hline Variable & FE model & SAR model \\
\hline $\mathrm{ENCO}_{i t}$ & $\begin{array}{l}-0.189 \\
(0.411)\end{array}$ & $\begin{array}{c}-0.185 \\
(-0.465)\end{array}$ \\
\hline $\mathrm{STAT}_{i t}$ & $\begin{array}{c}4.835^{* * *} \\
(1.243)\end{array}$ & $\begin{array}{c}4.804^{* * *} \\
(3.989)\end{array}$ \\
\hline $\mathrm{RESO}_{i t}$ & $\begin{array}{c}-0.625^{* *} \\
(0.268)\end{array}$ & $\begin{array}{l}-0.623^{* *} \\
(-2.400)\end{array}$ \\
\hline TRAN $_{i t}$ & $\begin{array}{l}1.048^{*} \\
(0.607)\end{array}$ & $\begin{array}{l}1.052^{*} \\
(1.789)\end{array}$ \\
\hline $\mathrm{HR}_{i t}$ & $\begin{array}{c}-0.648^{*} \\
(0.354)\end{array}$ & $\begin{array}{l}-1.887^{*} \\
(-1.328)\end{array}$ \\
\hline $\mathrm{INFO}_{i t}$ & $\begin{array}{c}0.136 \\
(0.102)\end{array}$ & $\begin{array}{c}0.136 \\
(1.374)\end{array}$ \\
\hline $\mathrm{p}$ & & $\begin{array}{c}-0.031 \\
(-0.275)\end{array}$ \\
\hline Log-likelihood & & 5.2193 \\
\hline Observations & 110 & 110 \\
\hline Number of province & 11 & 11 \\
\hline$R$-squared & 0.299 & 0.8100 \\
\hline
\end{tabular}

Note: ${ }^{*},{ }^{* *}$, and ${ }^{* * *}$ indicate significance at the levels of $10 \%, 5 \%$ and $1 \%$, respectively. Statistics are in parentheses.

presenting values of $4.862(p<0.01), 1.076(p<0.1),-0.641$ $(p<0.05)$, and $-0.656(p<0.1)$, respectively. The more the tourism industry is valued by the eastern provinces and cities, the more easily the development of the tourism industry will produce economies of scale and form a "magnetic field effect," such as talent, funds, and technology, which can not only optimize the industrial structure but also further improve scientific and technological content and technology and innovation spillovers of the tourism industry. Transportation is not only an important facet of tourism infrastructure but also an indispensable prerequisite for promoting the development of tourism. Transportation conditions greatly affect consumers' choices of tourism destinations, which will affect the development of tourism resources and of the whole tourism industry. Good traffic conditions can enable tourists to allocate more time and energy to "having fun" rather than to "travel." In other words, developed transportation networks can enhance the scale effect of tourism activities, help enhance the overall profits of tourism in specific regions, and improve the marginal output of tourism reception resources. It is worth noting that the effects of economic development and information levels do not pass the significance test. The empirical results of this article deviate from the traditional view that economic foundations and innovation ability must contribute to the improvement of industrial efficiency and further confirm that the growth of tourism efficiency in eastern provinces and cities in the studied period and region is not mainly derived from regional economic foundations or driven by innovation. The possible reasons for this are as follows: First, the level of economic development is not necessarily related to regional investment in tourism or the construction of tourism development infrastructure; second, the government-led characteristics of China's tourism development are evident. Compared with those invested in the primary and secondary industries and in other high-tech industries, fewer scientific research funds are invested in the tourism industry, which is considered a typical service industry. In the absence of external constraints, the scientific and technological innovation of tourism enterprises is limited, the application of informatization in tourism is not sufficient, and the role of informatization is relatively 
TABLE 7: Estimation results of direct, indirect, and total effects.

\begin{tabular}{lcccccc}
\hline Effect & $\mathrm{ENCO}_{i t}$ & $\mathrm{STAT}_{i t}$ & $\mathrm{RESO}_{i t}$ & $\mathrm{TRAN}_{i t}$ & $\mathrm{HR}_{i t}$ & $\mathrm{INFO}_{i t}$ \\
\hline \multirow{2}{*}{ Direct effect } & -0.180 & $4.862^{* * *}$ & $-0.641^{* *}$ & $1.076^{*}$ & $-0.656^{*}$ & 0.139 \\
& $(-0.482)$ & $(4.006)$ & $(-2.460)$ & $(1.877)$ & $(-1.961)$ & $(1.494)$ \\
Indirect effect & 0.001 & -0.089 & 0.015 & -0.025 & 0.015 & -0.003 \\
& $(0.010)$ & $(-0.155)$ & $(0.196)$ & $(-0.181)$ & $(0.181)$ & $(-0.152)$ \\
Total effect & -0.179 & $4.772^{* * *}$ & $-0.626^{* *}$ & $1.051^{*}$ & $-0.641^{*}$ & 0.136 \\
& $(-0.482)$ & $(3.559)$ & $(-2.408)$ & $(1.837)$ & $(-1.910)$ & $(1.470)$ \\
\hline
\end{tabular}

Note: ${ }^{*},{ }^{* *}$, and ${ }^{* * *}$ indicate significance at the levels of $10 \%, 5 \%$, and $1 \%$, respectively. $t$ statistics are in parentheses.

TABLE 8: Estimation results of the robustness test.

\begin{tabular}{lcccccc}
\hline Effect & $\mathrm{ENCO}_{i t}$ & $\mathrm{STAT}_{i t}$ & $\mathrm{RESO}_{t}$ & $\mathrm{TRAN}_{i t}$ & $\mathrm{HR}_{i t}$ & $\mathrm{INFO}_{i t}$ \\
\hline \multirow{2}{*}{ Direct effect } & -0.189 & $4.817^{* * *}$ & $-0.623^{* *}$ & $1.080^{*}$ & $-0.662^{*}$ & 0.138 \\
& $(-0.472)$ & $(3.981)$ & $(-2.337)$ & $(1.840)$ & $(-1.956)$ & $(1.426)$ \\
Indirect effect & 0.003 & -0.101 & 0.011 & -0.021 & 0.015 & -0.003 \\
& $(0.055)$ & $(-0.194)$ & $(0.153)$ & $(-0.159)$ & $(0.194)$ & $(-0.138)$ \\
Total effect & -0.187 & $4.717^{* * *}$ & $-0.611^{* *}$ & $1.059^{*}$ & $-0.647^{*}$ & 0.136 \\
& $(-0.475)$ & $(3.626)$ & $(-2.227)$ & $(1.782)$ & $(-1.911)$ & $(1.402)$ \\
\hline
\end{tabular}

Note: ${ }^{*},{ }^{* *}$, and ${ }^{* * *}$ indicate significance at the levels of $10 \%, 5 \%$, and $1 \%$, respectively. Statistics are in parentheses.

limited. The effect of tourism resource endowment and the labour force on tourism efficiency is negative. The possible reasons for this are as follows: the higher the resource endowment is, the more difficult it is to make full use of these resources, or the richness of tourism resources renders the problem of resource homogeneity more prominent and competition for tourism products more intense. The latter occurs because tourism is still a labour-intensive industry, and the low threshold of tourism employment leads to a large influx of personnel into the tourism industry. Excessive labour input is not conducive to the improvement of tourism efficiency. The quality of labour personnel is also an important aspect that has a different impact on tourism efficiency. The total spatial spillover effect is similar to the direct spatial spillover effect. Industrial status $(4.772, p<0.01)$ and traffic conditions (1.051, $p<0.1$ ) have a positive effect, tourism resource endowment $(-0.626, p<0.05)$ and the labour force $(-0.641, p<0.1)$ have a negative effect, and the level of economic development and informatization do not pass the significance test.

To eliminate possible endogeneity problems in our data, the geographic distance spatial weight matrix is used to replace the geographical adjacency matrix to test the robustness of the factors that influence tourism comprehensive efficiency and its spatial spillover effect (Table 8). The results show that the benchmark regression results remain unchanged, indicating that the robustness test has the ideal effect.

\section{Conclusion and Discussion}

5.1. Conclusion. Using the static super efficiency DEA model, dynamic Malmquist index, and spatial econometric model, this article systematically analysed the panel data of 11 eastern provinces for 2010 to 2019 and measured levels of and differences in tourism efficiency in the time and space dimensions. This article further explored the state and influencing factors of the temporal and spatial differentiation of tourism efficiency in these 11 provinces and cities. Our specific conclusions are as follows:

(1) From the static data, the average level of tourism efficiency in eastern provinces for the last ten years is higher than 1, and it has been at a relatively high level overall. However, in terms of tourism efficiency in specific time periods, there are still great differences in the spatial distribution. The leading two cities in terms of average efficiency, with values of above 1.5, are Hebei and Tianjin, while Hainan has the lowest average efficiency level of only 0.588 . At the same time, the efficiency values for different years and different provinces and cities have been affected by multiple factors and have changed sporadically, resulting in no obvious trends in the interior region.

(2) In terms of dynamic index changes, the Malmquist index of the overall tourism efficiency of eastern provinces and cities is 1.062 for the past 10 years and is on the rise. Among the contributions of each index to the tourism efficiency total factor productivity index, the change index of technical efficiency is the highest, the change index of scale efficiency is the second highest, and the change index of pure technical efficiency is relatively low. Among provinces and cities, the improvements of the total factor productivity index in Tianjin, Hebei, Liaoning, Shanghai, Jiangsu, Zhejiang, and Fujian are jointly driven by comprehensive efficiency and technological progress efficiency, while improvements of the total factor productivity index in Beijing, Guangdong, Shandong, and Hainan are mainly driven by technological progress efficiency.

(3) From the spatial autocorrelation test and calculation obtained from a spatial econometric model, the tourism efficiency of eastern provinces and cities 
shows obvious signs of temporal and spatial differentiation and spatial correlation for the past decade. In terms of influencing factors, industrial status and traffic conditions have a significantly positive effect on tourism efficiency; tourism resource endowment and the labour force have a negative effect, economic development and information levels do not pass the significance test, and changes in provincial and municipal tourism efficiency are jointly affected and driven by a variety of factors.

In summary, the overall tourism efficiency of the 11 eastern provinces and cities studied is relatively high, and the annual average efficiency level is relatively stable. However, compared with that in the subdivided regions, tourism efficiency across the studied provinces and cities varies greatly. However, overall tourism efficiency is still increasing and can be further improved in terms of technical, scale, and pure technical efficiency, especially in provinces and cities with low efficiency values. Eastern provinces and cities show obvious patterns of temporal and spatial differentiation in terms of tourism efficiency and spatial correlation. Industrial status, traffic conditions, tourism resource endowment, and the labour force are the main factors driving this differentiation.

5.2. Discussion. Since the institution of the country's reform and opening up policy, China's tourism has developed rapidly. Policy support, capital investment, and scientific planning have in turn undergone more significant progress. The healthy development of tourism and change in tourism efficiency have been affected by multiple factors, including the development status of provinces and cities, industrial development maturity, capital investment, the allocation of resources, and scientific levels [34, 35]. As an important facet of tourism development quality, tourism efficiency is of important practical significance for expanding the scale of tourism development, improving the comprehensive competitiveness of tourism, and realizing the sustainable development of tourism. Examining the development and evolution of tourism efficiency can help tourism in China develop in a more effective manner. Based on the above discussion and analysis of tourism efficiency and its decomposition efficiency in China's eastern provinces from 2010 to 2019, the following discussion considers efficiency levels, efficiency changes, and temporal and spatial differentiation and corresponding influencing factors.

(1) For eastern provinces and cities, technical and scale efficiency influence each other and more significantly affect tourism efficiency. Therefore, existing technical conditions should be utilized to increase scale efficiency such that scale and technical efficiency can be effectively combined to inject improve tourism efficiency in China's eastern provinces and cities.

(2) There are significant regional differences in tourism efficiency across eastern provinces and cities. This unbalanced pattern is closely related to the industrial status of tourism across provinces and cities, regional traffic conditions, the development and utilization of tourism resources, and the absorption of the labour force. Therefore, we should pay attention to changing tourism's industrial structure and improving the utilization efficiency of resource elements, constantly improving regional traffic conditions and the industrial environment, enriching the workforce, and realizing a more balanced and consistent development of tourism efficiency in China's eastern provinces and cities.

This study presents some shortcomings, which are as follows. Due to the complexity and comprehensiveness of the tourism industry, the selection of input indicators must be further improved. The optimization and reorganization of the spatial network of tourism efficiency is controlled by multiple factors, but the discussion of the impacts of various factors on tourism efficiency is still slightly insufficient. In view of a lack of tourism statistical data, the use of alternative index data may lead to biased results, which must be addressed in follow-up studies.

\section{Data Availability}

The data used to support the findings of this study are available from the corresponding author upon request.

\section{Conflicts of Interest}

The authors have no conflicts of interest to declare.

\section{Acknowledgments}

This work was funded by the National Natural Science Foundation of China (No. 41671140).

\section{References}

[1] M. J. Farrell, "The measurement of productive efficiency," Journal of the Royal Statistical Society: Series A, vol. 120, no. 3, pp. 253-278, 1957.

[2] B. Zhou, Y. Xu, and S. K. Lee, "Tourism development and regional production efficiency: evidence from southwestern China," Tourism Economics, vol. 25, no. 5, pp. 800-818, 2019.

[3] S. Chaabouni, "China's regional tourism efficiency: a twostage double bootstrap data envelopment analysis," Journal of Destination Marketing and Management, vol. 11, no. 3, pp. 183-191, 2019.

[4] C. D. Köksal and A. A. Aksu, "Efficiency evaluation of A-group travel agencies with data envelopment analysis (DEA): a case study in the Antalya region, Turkey," Tourism Management, vol. 28, no. 3, pp. 830-834, 2007.

[5] O. Mhlanga, "Factors impacting airline efficiency in Southern Africa: a data envelopment analysis," GeoJournal, vol. 84, no. 3, pp. 759-770, 2019.

[6] K. Wang, H. Lin, C. Gan, and C. Deng, "Spatio-temporal coupling relationship between tourism poverty alleviation efficiency and economic development level in contiguous destitute areas: a case study of Wuling mountain," Economic Geography, vol. 40, no. 2, pp. 200-208, 2020.

[7] S. Wang, Y. Chu, A. Guo, and Y. Guo, "Study on high quality development of tourism economy in 18 key provinces along 
the one belt and one road initiative: based on the measurement of tourism resource conversion efficiency," Scientia Geographica Sinica, vol. 40, pp. 1505-1512, 2020.

[8] Z. Yao, T. Chen, S. Yin, and X. Li, "Regional tourism ecoefficiency Model and an empirical research of Hainan province," Scientia Geographica Sinica, vol. 36, pp. 417-423, 2016.

[9] Y. Fang, Z. Huang, D. Li, and F. Wang, "The measurement of Chinese provincial tourism developing efficiency and its spatio-temporal evolution," Economic Geography, vol. 35, no. 8, pp. 189-195, 2015.

[10] X. Ma, "Progress and trend of tourism efficiency research home and abroad," Human Geography, vol. 27, no. 3, pp. 11-17, 2012.

[11] Z. Wang and Q. Liu, "The evolution and influencing factors of spatial network structure of China's provincial tourism efficiency," Scientia Geographica Sinica, vol. 41, pp. 397-406, 2021.

[12] K. Wang, Z. Huang, Y. Tao, and Y. Fang, "Study on spatial characteristics and spillover effects of urban tourism efficiency: a case of Yangtze river delta," Economic Geography, vol. 33, no. 4, pp. 161-167, 2013.

[13] P. Shen, N. Zhou, Y. Zhang, K. Wang, and Z. Li, "Spatiotemporal evolution and influencing factors of tourism industry efficiency in Jiangsu province based on Dea-Malmquist index secondary decomposition model," Resources and Environment in the Yangtze Basin, vol. 27, pp. 53-62, 2018.

[14] Q.-l. Pan, Y.-q. Song, L. Chen, and Z.-k. Pan, "The spatial pattern and influencing factors of county-scale tourism efficiency in Shaanxi province," Journal of Natural Resources, vol. 36, no. 4, pp. 866-878, 2021.

[15] F. Cao, Z. Huang, M. Xu, and K. Wang, "Spatial-temporal pattern and influencing factors of tourism efficiency and the decomposition efficiency in Chinese scenic areas: based on the Bootstrap-DEA method," Geographical Research, vol. 34, pp. 2395-2408, 2015.

[16] Z. Ding, Q. Lai, X. Huang, J. Zhu, and P. Lin, "Study on the spatial differences and convergences of the tourism efficiency in the Forest parks of China," Forestry Economics, vol. 38, no. 11, pp. 41-48, 2016.

[17] A. Paul, D. William, and H. Gao, Economics, Economic Science Press, Beijing, China, 1991.

[18] H. Deng and L. Lu, "The urban tourism efficiencies of cities in Anhui province based on DEA model," Journal of Natural Resources, vol. 29, pp. 313-323, 2014.

[19] J. Wei, J. Hu, and L. Zhu, "Spatial-temporal evolution and influence mechanism of tourism development efficiency in Hubei and Anhui provinces," Economic Geography, vol. 38, no. 8, pp. 187-195, 2018.

[20] F. Cao, Z. Huang, and F. Yu, "The spatial evolution of travel efficiency of China's national scenic areas and its driving mechanism," Geographical Research, vol. 33, no. 6, pp. 11511166, 2014.

[21] F. Martínez-Roget and X. A. Rodríguez, "Occupancy level and productivity in rural tourism establishments: the case of Galicia, Spain," Tourism Economics, vol. 12, no. 2, pp. 279-289, 2006.

[22] M. Jiang, N. Zhou, and Y. Liang, "The difference of regional tourism spatial structure in Jiangsu province based on aggregation and fractal," Resources and Environment in the Yangtze Basin, vol. 21, no. Z2, pp. 81-88, 2012.

[23] K. Wang, Z. Huang, F. Cao, F. Yu, and F. Tang, "Spatial pattern evolution of urban tourism performance and its influence factors in Pan-Yangtze river delta," Journal of Natural Resources, vol. 31, pp. 1149-1163, 2016.

[24] A. Charnes, W. W. Cooper, and E. Rhodes, "Measuring the efficiency of decision making units," European Journal of Operational Research, vol. 2, no. 6, pp. 429-444, 1978.

[25] Q. Wei, Data Envelopment Analysis, Science Press, Beijing, China, 2004.

[26] P. Andersen and N. C. Petersen, "A procedure for ranking efficient units in data envelopment analysis," Management Science, no. 39, pp. 1261-1265, 1993.

[27] J. Hua and C. Ye, "Urban land use efficiency and spatiotemporal differentiation of Guangdong province based on DEA," Research of Soil and Water Conservation, vol. 25, pp. 283-288, 2018.

[28] S. Xu, S. Fang, Y. Gan, and X. Qin, "Measurement and spatiotemporal evolution of tourism poverty alleviation efficiency in Guangxi border ethnic areas," World Geographical Studies, vol. 30, no. 2, pp. 367-377, 201.

[29] R. Fare, S. Grosskopf, and M. Norris, "Productivity growth, technical progress, and efficiency change in industrialized Countries," The American Economic Review, vol. 84, no. 1, pp. 66-83, 1994.

[30] L. Anselin, "Spatial externalities, spatial multipliers, and spatial econometrics," International Regional Science Review, vol. 26, no. 2, pp. 153-166, 2003.

[31] J. P. Elhorst, "Dynamic spatial panels: models, methods and inferences," Spatial Econometrics, Springer, Berlin, Heidelberg, Germany, 2014.

[32] R. M. Auty, Sustaining Development in Mineral Economies: The Resource Curse Thesis, Routledge, London, UK, 1993.

[33] J. LeSage and R. K. Pace, Introduction to Spatial Econometrics, Chapman and Hall/CRC, Boca Raton, FL, USA, 2009.

[34] T. Yu, B. Zuo, X. Song, and Y. Wu, "The influence of tourism development on regional economic efficiency: evidence from 283 prefecture-level cities in China," Geographical Research, vol. 39, no. 6, pp. 1357-1369, 2020.

[35] Y. Fang, M. Xie, D. Bi, and Y. Xiao, "An exploratory analysis on the spatial correlation characteristics and influential factors of inbound tourism in China: a geographical weighted regression perspective," Tourism Science, vol. 28, no. 3, pp. 22-35, 2014. 